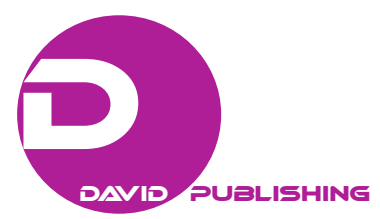

\title{
Reform of Teaching of English Literature for English Majors in China
}

\author{
Xia Hou, Chao Lei \\ Zhoukou Normal University, Zhoukou, China
}

\begin{abstract}
English literature for English majors of China has entered university syllabuses since 1950s. It is regarded as one of the prominent subjects in the advanced English study. However, as the time passes, a series of problems appear. The interest of English teachers and students toward literature has skidded to the lowest point. This paper tries to explore the main aims and contemporaries of literature teaching and point out the reasons and settlements of this problem.
\end{abstract}

Keywords: reform, English majors of China, English literature

\section{Introduction}

"Broadly speaking, literature is a way to approach foreign culture to the greatest extent and a continuation of early background learning” (Christopher, 2006, p. 180). Literature is the carrier of language and language is the expression of literature. Language and literature complements each other and constructs each other. According to Professor Gu Zhengkun's principle of Interactive Linguistics, human culture is largely controlled by language. Cultural structure in turn embodies and carries the language structure. Therefore, literature learning is conducive to language learning. The purpose of literature teaching is not only for language learning, but also for social background, cultural characteristics, and humanistic spirit. However, with the prosperity of economy in China, many teachers and students believe that the focus of foreign language learning lies in mastering language skills, making the subject instrumental, and bringing direct economic benefits to their own work. Therefore, we neglect or even give up the study of literature and turn to writing, speaking, and translation. Starting from the purpose and current situation of literature course, this paper analyzes the causes and puts forward solutions.

\section{The Purpose of English Literature Teaching in China}

Literature is a concentrated reflection of a country's society, economy, culture, politics, art, and history. According to the requirements of English Teaching Syllabus for English Majors in Colleges and Universities, “The purpose of literature course is to cultivate students' ability to read, appreciate, and understand English literature originals, and master the basic knowledge and methods of literary criticism. By reading and analyzing English and American literary works, we can improve students' basic language skills and humanistic quality, and enhance their understanding of Western literature and culture”. Therefore, the purpose of literature teaching

Xia Hou, M.A., associate professor, College of Foreign Languages, Zhoukou Normal University. Chao Lei, M.A., professor, College of Foreign Languages, Zhoukou Normal University. 
is not only to provide how much text information or grammar translation at the level of language, but also to cultivate students' ability of critical analysis, imagination, appreciation of wisdom, and culture, and to use a positive attitude to contact life, solve problems, and express opinions. Literature curriculum can be divided into four levels: "language level, style level, content level, and ideological level” (Christopher, 2006, p. 178). Language level is the core of all foreign language teaching, and the most basic communication is through learning language structure. Stylistic level is an important basis for students to distinguish writing styles of different writers in different historical periods from the elegant English in ancient times to the informal style in modern times. At the content level, it obviously refers to the content expressed in the work, including time, place, character and plot, etc. The ideological level refers to the ideology reflected by the works or the symbolic meaning inside the works. Through the study of this level, students can easily understand the theme and significance of the article.

The real goal of literature course is not simply to aim at advanced language, but to pay more attention to the development and broadening of literature ability, that is, the last three levels of literature course. Culler uses a classical discourse to illustrate the importance of cultivating literary competence. "Anyone who does not know literature or does not know how to read a novel will know nothing about the poem in front of him. Although language knowledge can make him understand the meaning of phrases and sentences, he will not understand the connection and combination of phrases from the perspective of literature. He cannot read literature, because he lacks the literary ability to connect things. He has not internalized the 'grammar' of literature. This kind of 'grammar' can be transformed into literary structure and meaning” (Christopher, 2006, p. 185).

\section{The Current Situation in English Literature Teaching of China}

Literature course plays an important role in senior English majors. However, due to subjective and objective reasons, the status of literature course is declining day by day, and the level of teaching is also descending.

First of all, the content of English literature teaching has been greatly reduced. Most of the literature textbooks are compiled according to four class hours a week. But many colleges and universities do not meet the required class hours. There are only 72 class hours in an academic year. Time, content, and difficulty bring great resistance to literature course. And most of the textbooks are the old versions of the 20th century, focusing on the middle ancient literature until modern literature, but there is little research on contemporary literature. Among them, Asian American literature and Black literature are not paid much attention to. Secondly, some students are not interested in literature. They think that it is a waste of time to read one or several works for a period of time, and they do not understand the contents of the works, or even forget to read them. It is better to read science fiction or detective stories with strange plots and high interest. Thirdly, in order to let students have an overall understanding of literature in a short period of time, teachers adopt a single cramming mode, ignoring classroom discussion and thesis writing. Teachers' analysis of texts has replaced the students' ability of reading. Students have been passively accepting the teachers' "retelling", and it is difficult for them to construct their own opinions on literary works. Literature selective reading stays at the stage of supplement to literature history. This teaching mode not only destroys the integrity of the works, but also ignores the cultivation of students' ability to analyze and criticize them. 


\section{Reasons of Problems in English Literature Teaching of China}

With the development of society and the globalization of the world economy in recent years, on the one hand, people have realized the importance of foreign language learning, and on the other hand, they have also introduced the utilitarianism into foreign language learning. Practical majors and courses, such as Foreign Trades English, Business English, Tourism English, Science and Technology English, and Job-Hunting English, have come into being. This kind of pragmatism and the thought of attaching importance to skills, but neglecting humanities are impacting the teaching of literature course. As a result, many students learn English in order to obtain certificates or master a tool to earn money. Some students are not interested in literature, which is a time-consuming and laborious subject without much economic benefits. Most of the students focus on the courses with strong practicability. However, teachers' teaching methods and mentality are also a subjective factor restricting the smooth implementation of literature classes. The effect of teaching is closely related to teachers. The stronger the teacher's ability is, the better the teaching effect is. The more popular the teacher is with the students, the more enthusiastic the students are to learn. Due to the long history span, many literary schools, various writers' styles, and different cultural thoughts and language characteristics in different periods, literature teachers are required to have solid professional basic knowledge and theoretical accomplishment of Chinese and Western literature. At the same time, literature is the cultural representation of life experience. Literary works contain rich thinking, value orientation, and specific ideology of life, so literature teachers need to have profound humanistic basic knowledge. However, many teachers do not have a solid professional foundation and weak humanistic spirit. They blindly pursue the number of papers and the promotion of professional titles, regard teaching as a sideline, and do not attach importance to the relationship between the humanistic spirit in literary works and actual life.

\section{Reform of English Literature Curriculum}

The teaching reform of English literature is imperative and has a long way to go. If we do not correct people's wrong understanding of literature and abnormal teaching mode as soon as possible, and set up the humanistic teaching idea in colleges and universities. The higher education in colleges and universities will survive in name. Through several years of teaching experience and practical research, the author comes to the following suggestions.

\section{Reform the Arrangement of Literature Textbooks}

English literature has a long history. Especially, after the 20th century, the British and American literature presented a colorful prosperity because of the great influence brought by the intense turbulence of the world situation. With the reform and opening up of China. The research on the history of literature is more and more in-depth, and there are more and more works and reviews. However, due to the difficulty of writing literary history and the approach of the times, there are few books written for Chinese students to systematically discuss literary history in English. The traditional teaching materials, which greatly reduces the enthusiasm of students. However, the modern literature is the end of the traditional teaching materials, which lacks the discussion of the contemporary part. The reform of teaching materials is imperative.

The author thinks that teaching material should first provide a panorama of British and American literature, and display the key and difficult points, literary history and mutual relations of the two literatures in a graphic way, so as to provide students with centralized memory and general understanding. Its content is divided into 
two parts: "English literature” and "American literature”. In the part of "English literature”, it is divided into six parts according to the medieval and renaissance period, the enlightenment period, the romanticism period, the Victorian period, the modern period, and the contemporary period; in the part of "American literature", it is divided into four parts according to the early and romanticism period, the realism period, the modern period, and the contemporary period. Then, starting from the definition of literature, it analyzes the concept, classification, and curriculum requirements of literature. According to the types of literature, it can be divided into four parts: novel, drama, poetry, and prose. According to the four categories and the order of the works, arrange the contents (the combination of British and American literature is conducive to the induction and differentiation of works and characteristics in the same period and the law of literary development). Try to let students start with the most comprehensible novel, enhance their interest, and deepen their understanding. And through the classification and explanation of literature, we can understand the connotation of the article. In the arrangement, we should innovate boldly, break through the tradition of compiling the history of literature, combine the types of literature with the history of literature and the historical background, the influence of characters, the explanation of terms, etc., so that students can quickly classify and deeply understand the writers and works in a specific historical environment, and absorb the essence of literary works. It is expected that this can greatly shorten the class hours of literature teaching and enable students to get comprehensive literature knowledge to the greatest extent.

\section{Establish Students' Humanistic Spirit}

Humanistic spirit is manifested in the maintenance and pursuit of human dignity, value, and destiny, the cherishing of spiritual culture left behind by human beings and the shaping of ideal personality. While humanistic discipline is an educational system that focuses on the expression of humanistic spirit, which focuses on human value. Higher education not only imparts scientific knowledge to students, but also more importantly, educates people and pursues the improvement of humanistic spirit. There is rich humanistic spirit in English literature course. Therefore, students are required to pay attention to this course in ideology. Students can strive to explore the value and significance of life on the basis of textbooks. We should inherit and carry forward the excellent traditions of all ethnic groups, and abandon and reject the negative and degenerate ideas.

The level of a country's humanistic cultivation, to a great extent, depends on the level of humanistic education. The level of students' humanistic spirit affects the construction of China and the future of our nation. Virtue is the teacher and conduct is the model. Therefore, college teachers must start from themselves, not only to teach literature knowledge and introduce literature works, but also to learn rich humanistic spirit nutrition from the works to cultivate students' ideological and moral level.

\section{Change the Teaching Mode of Teachers}

English literature emphasizes Humanism, the most important of which is people-oriented. Therefore, the teaching method of "learners centered" should be implemented in classroom teaching. In the whole teaching process, teachers should set up correct roles, that is, "controller, assessor, organizer, promoter, participant, and resources” (Huang \& Zhang, 2003, p. 138). Based on this, there are the following teaching methods with good effects through a large number of teaching practices:

Reading. Literature course is short of time and has many tasks, which requires teachers to arrange students to read works or excerpts after class to understand the main content or plot. Lay a good foundation and preparation for teaching. This not only saves teaching time, but also improves the ability of self-study. 
Paraleukorrhea. "The use of cultural aside refers to the introduction of relevant cultural knowledge in foreign language teaching, so that students can have a more comprehensive, more vivid, and more concentrated understanding of foreign culture” (Huang \& Zhang, 2003, p. 138). For example, when explaining Beowulf, a work in the history of British literature, we should first intersperse the epic of the nation and the relevant knowledge of the social situation in Britain at this stage. In this way, students can have a general understanding from the macro level, which plays an important role in further analysis of works.

Audio-visuality. After the introduction and analysis of the work, the teacher should provide the opportunity to enjoy the film if possible. This can greatly improve the interest of students. But we should pay attention to that we should watch it in the late self-study time instead of taking up the teaching time. In this way, we can make full use of our spare time to make an intuitive display of the textbook content.

Discussion. After having a comprehensive understanding of the work, teachers should raise some representative questions and organize discussion in class. We should give full play to our thinking ability and actively express our views. When there are different opinions, the class adopts the way of debate, so that students can get more inspiration and fun of learning and exploration while arguing with each other.

Performance. In the absence of film and television materials, students can be organized to set up a drama troupe to make up, guide, and perform by themselves. Actors deepen their understanding of the works while creating plays and performing. And the audience students can understand the works more intuitively. Some forms of literature, such as poetry and prose, can be read aloud by members of the drama troupe emotionally or independently created with their imagination according to their works.

Thesis. After students appreciate it, teachers should arrange homework in time and let students express their opinions by means of papers. Improve the ability to express and analyze problems. Cultivate humanistic spirit in thinking and discipline ability in writing.

Comparison. "The method of comparative analysis" (Huang \& Zhang, 2003, p. 138) can be used in cultural comparison. Teachers guide students to try to compare and analyze the Chinese and foreign works in order to deepen the local consciousness of literature. We can also try to analyze English literary works with Chinese traditional cultural thinking. For example, when learning Bacon's On Study, we can compare Xunzi’s On Learning. We should learn from each other's strengths and make up for each other's weaknesses, so as to achieve common prosperity.

In a word, through the reform of literature teaching, teachers should give full play to their creativity, mobilize the enthusiasm of students, and cultivate their humanistic spirit. However, the times are always improving, people's cognition should be changed accordingly, and the teaching mode should be changed accordingly. Therefore, the reform of literature course is imperative and endless.

\section{Conclusions}

We should innovate boldly, break through the tradition of compiling the history of literature, combine the types of literature with the history of literature and the historical background, the influence of characters, the explanation of terms, etc., so that students can quickly classify and deeply understand the writers and works in a specific historical environment, and absorb the essence of literary works. It is expected that this can greatly shorten the class hours of literature teaching and enable students to get comprehensive literature knowledge to the greatest extent. The level of a country's humanistic cultivation, to a great extent, depends on the level of humanistic education. The level of students' humanistic spirit affects the construction of China and the future 
of our nation. Virtue is the teacher and conduct is the model. Therefore, college teachers must start from themselves, not only to teach literature knowledge and introduce literature works, but also to learn rich humanistic spirit nutrition from the works to cultivate students' ideological and moral level.

In a word, through the reform of literature teaching, teachers should give full play to their creativity, mobilize the enthusiasm of students, and cultivate their humanistic spirit. However, the times are always improving, people's cognition should be changed accordingly, and the teaching mode should be changed accordingly. Therefore, the reform of literature course is imperative and endless.

\section{References}

Christopher, B. (2006). Ronald Carter: Literature and language teaching (pp. 171-190). Shanghai: Shanghai Foreign Language Education Press.

Huang, S. Q., \& Zhang, Z. G. (2003). On the reform of teaching methods of British and American literature for English majors in colleges and universities. Journal of Gannan Normal University, 6, 137-138.

Lu, G. Q. (2008). Curriculum reform of English and American literature teaching for humanities and college English majors. Foreign Language Teaching Research, 11, 73-75. 